\title{
O ENFOQUE DO EMPREENDEDORISMO NOS CURSOS DE ADMINISTRAÇÃO DO ESTADO DE SANTA CATARINA
}

\author{
Fernando Sergio Mazon ${ }^{1}$ \\ Jardel Affonso Seibel ${ }^{2}$ \\ Luana Pagliari ${ }^{3}$ \\ Maiara Bordin ${ }^{4}$
}

\begin{abstract}
RESUMO: O empreendedorismo é defendido como uma possível solução para os problemas sociais e, segundo diversos autores, pode ser ensinado em escolas e universidades. Por isso, este artigo tem o objetivo de investigar a abordagem do empreendedorismo nos cursos de graduação em Administração das universidades do estado de Santa Catarina. O referencial teórico apresenta alguns conceitos básicos acerca do empreendedorismo. O estudo se constitui de uma pesquisa descritiva, com a utilização de dados secundários coletados nas páginas das universidades na internet. Foram pesquisados ao todo 116 cursos de Administração e constatou-se que mais de uma centena dos cursos é ofertado por instituições privadas. Há o predomínio da graduação com quatro anos de duração e com apenas uma disciplina de empreendedorismo sendo ministrada ao longo do curso.
\end{abstract}

Palavras-chave: Empreendedorismo. Empreendedor. Cursos de Administração.

${ }^{1}$ Professor do Curso de Administração na Universidade Regional Integrada do Alto Uruguai e das Missões (URI). Universidade Regional Integrada do Alto Uruguai e das Missões (URI) Campus de Erechim. Rio Grande do Sul. Brasil. E-mail: fernando.mazon@yahoo.com.br

${ }^{2}$ Acadêmico do Curso de Administração na Universidade Regional Integrada do Alto Uruguai e das Missões (URI). Universidade Regional Integrada do Alto Uruguai e das Missões (URI) Campus de Erechim. Rio Grande do Sul. Brasil. E-mail: jardelfront@gmail.com

${ }^{3}$ Acadêmica do Curso de Administração na Universidade Regional Integrada do Alto Uruguai e das Missões (URI). Universidade Regional Integrada do Alto Uruguai e das Missões (URI) Campus de Erechim. Rio Grande do Sul. Brasil. E-mail: Iuanapagliari92@gmail.com

${ }^{4}$ Acadêmica do Curso de Administração na Universidade Regional Integrada do Alto Uruguai e das Missões (URI). Universidade Regional Integrada do Alto Uruguai e das Missões (URI) Campus de Erechim. Rio Grande do Sul. Brasil. E-mail: maia bordin@hotmail.com 


\title{
THE ENTREPRENEURSHIP APPROACH IN THE COURSES OF ADMINISTRATION OF THE STATE OF SANTA CATARINA
}

\begin{abstract}
Entrepreneurship is said to be a possible solution to social problems and, according to several authors, it can be taught in schools and universities. Therefore, the aim of this article is to investigate the entrepreneurship approach in graduation courses of Administration at universities located in Santa Catarina State. The theoretical background presents some basic concepts about entrepreneurship. The study consists of a descriptive research, with the use of secondary data collected from the universities' web pages. A total of 116 Administration courses were surveyed and it was verified that more than a hundred of the courses are offered by private institutions. There is a predominance of graduation with four years of duration and only one subject of entrepreneurship being taught throughout the course.
\end{abstract}

Keywords: Entrepreneurship. Entrepreneur. Administration Courses.

\section{INTRODUÇÃO}

De acordo com Crecente-Romero, Giménez-Baldazo e Rivera-Galicia (2018), a Teoria do Capital Humano afirma que quanto maior o nível educacional de uma pessoa, maior a sua produtividade e ganhos. Mukesh, Rao e Rajasekharan (2018) sustentam então que a educação empreendedora aumenta o potencial empreendedor dos estudantes, conduzindo-os para uma carreira empreendedora.

Especialmente em tempos de dificuldades econômicas, o empreendedorismo é evidenciado e suscita algumas questões: $O$ que significa empreender? $\mathrm{O}$ empreendedorismo é algo que pode ser ensinado? Que importância é conferida a ele nas universidades?

Um dos pioneiros na abordagem do empreendedorismo foi Schumpeter (1947, 1982). Para ele, o empreendedor está associado à inovação e ao desenvolvimento econômico. Dolabela (1999) contribui descrevendo que o pesquisador que verdadeiramente iniciou a contribuição das ciências do comportamento para o estudo do empreendedorismo foi McClelland (1965), ao afirmar que os empreendedores possuíam uma grande necessidade de realização e, com isso, tinham a motivação para empreender.

No Brasil, as principais instituições que realizam atividades com o intuito de estimular e disseminar o empreendedorismo são o SEBRAE (Serviço Brasileiro de 
Apoio à Micro e Pequena Empresa) e a Endeavor/Brasil. Por entenderem que o empreendedorismo é importante para a sociedade, que ele pode (e deve) ser ensinado, estas duas instituições realizaram em 2016 a quarta edição da pesquisa "Empreendedorismo nas Universidades Brasileiras". Esta pesquisa permitiu traçar um perfil de como ele vem sendo trabalhado nas universidades brasileiras e também como ele é percebido por parte de alunos e professores.

Este trabalho toma por consideração que as universidades são agentes importantes para a disseminação do conhecimento e na promoção do desenvolvimento das regiões em que estão inseridas, e que o curso de Administração é o que mais tem proximidade/afinidade com o tema do empreendedorismo. Com esta concepção e tendo a pesquisa da Endeavor/SEBRAE como referência, buscou-se entender: qual a importância/enfoque concedido ao empreendedorismo nos cursos de Administração do estado de Santa Catarina?

A quantidade e distribuição das disciplinas ao longo do curso pode influenciar os resultados na formação de empreendedores. Desta forma, o trabalho tem o objetivo de identificar quantas disciplinas de empreendedorismo são trabalhadas ao longo dos cursos de graduação em Administração no estado de Santa Catarina e como elas estão distribuídas na grade curricular. Assim, a pesquisa tem a oportunidade de contribuir para o planejamento dos cursos e com qualidade dos empreendedores que as universidades formam para a sociedade.

\section{EMPREENDEDORISMO}

O empreendedorismo é um fenômeno socioeconômico que tem sido valorizado em virtude da sua influência no crescimento e desenvolvimento de economias regionais e nacionais (ROCHA; FREITAS, 2014). Várias são as definições para os termos "empreendedor" ou "empreendedorismo". O empreendedorismo é um neologismo derivado da livre tradução da palavra entrepreneuship e utilizado para designar os estudos relativos ao empreendedor, às suas características e à sua atuação (DOLABELA, 1999).

Hisrich e Peters (2004) entendem que o termo empreendedorismo seria derivado do francês entrepreneur. Originalmente, teria como significado "o que está no meio" ou "entre compradores". Siqueira e Guimarães (2002) complementam que 
a palavra entrepreneur, utilizada já no século XVIII e derivada do verbo francês entreprendre, significava assumir empreitadas que exigiam muito esforço, referindose a pessoas que organizavam e lideravam expedições militares. Entretanto, desde a Idade Média o conceito esteve relacionado ao ato de assumir riscos, principalmente em atividades comerciais (BECKER; LACOMBE, 2003).

O economista e cientista político Joseph Alois Schumpeter não foi o criador do termo empreendedorismo, mas foi quem impulsionou o tema. Para ele, o empreendedor está associado à inovação e ao desenvolvimento econômico. Na concepção de Schumpeter $(1947,1982)$, a inovação é o fenômeno principal do desenvolvimento econômico e o empreendedor tem a função de realizar essa inovação.

O autor entende que o empreendedorismo é um processo de "destruição criativa", fazendo com que os produtos ou métodos de produção existentes sejam destruídos e substituídos por novos. Seriam papéis do empreendedor: a inovação, a assunção de riscos e o permanente rompimento dos paradigmas estabelecidos. Por meio de suas ações inovadoras, da assunção dos riscos e do rompimento dos paradigmas existentes, o empreendedor pode introduzir descontinuidades cíclicas na economia e, assim, impulsionar o desenvolvimento econômico em âmbito micro ou macrorregional (SCHUMPETER, 1982; BECKER; LACOMBE, 2003).

Barreto (1998) segue a mesma linha de raciocínio de Schumpeter (1982) e entende que o empreendedorismo é habilidade de criar e constituir algo a partir de muito pouco ou de quase nada. É o desenvolvimento de uma organização em oposição a observá-la, analisá-la ou simplesmente descrevê-la.

Alguns autores complementaram as ideias de Schumpeter (1992), que tinha seus estudos pautados essencialmente sob o prisma econômico, ao focarem suas pesquisas nos aspectos comportamentais, ou seja, como o perfil e as características pessoais fazem com que uma pessoa se torne um empreendedor. Dolabela (1999) descreve que o pesquisador que verdadeiramente iniciou a contribuição das ciências do comportamento para o estudo do empreendedorismo foi David C. McClelland, ao afirmar que os empreendedores possuíam uma grande necessidade de realização e, com isso, tinham a motivação para empreender (McCLELLAND, 1965).

Em uma abordagem menos economicista e mais comportamental, Dolabela (2010) descreve que o empreendedor é alguém que sonha e busca transformar seu 
sonho em realidade e em riqueza. Desta forma, o empreendedor não necessariamente seria um "criador" de empresas, mas alguém capaz de colocar em prática os objetivos ou motivações pessoais ou coletivas.

Muitos defendem o empreendedorismo como um mecanismo para o crescimento econômico e como uma possível solução para os problemas sociais. Neste sentido, sua compreensão e seu estímulo são importantes para as instituições. North (1990) enfatiza que as instituições podem ser compreendidas como "regras do jogo" em uma sociedade e, formalmente, são as limitações idealizadas pelo homem, as quais dão forma e regem a interação humana. Estas "regras do jogo" seriam os direitos de propriedade, o direito comercial, os trâmites burocráticos para a abertura de empresas, ideias, crenças, valores, o que afetaria a criação e o desenvolvimento de novos empreendimentos.

North (1990) ainda descreve que as instituições têm o propósito de reduzir as incertezas próprias da interação humana. Para o autor, essas incertezas existem em consequência da complexidade dos problemas a serem resolvidos. Já Toyoshima (1999) entende que as instituições têm como papel principal reduzir as incertezas existentes no ambiente, cirando estruturas estáveis que regulem a interação entre os indivíduos.

O processo de empreender inicia quando uma ou mais pessoas reconhecem uma oportunidade como potencial para criar algo novo (produtos, serviços, processos de produção, gestão, etc.). As oportunidades surgem por meio de condições de mudança - cenário social, político, econômico e demográfico - e devem ter potencial para gerar valor econômico, pois é muito valorizado na sociedade atual (BARON; SHANE, 2011).

Dolabela (1999) defende que o empreendedorismo deve ser estimulado em virtude do decréscimo contínuo de postos de trabalhos no mundo inteiro. Para que isso seja possível, Dornelas (2001) cita que uma das soluções pode ser encontrada no sistema educacional, por meio da oferta de cursos e matérias de empreendedorismo. Esta seria uma alternativa principalmente aos jovens, que estão iniciando sua carreira profissional.

Com isso, as escolas e universidades assumem um papel central na difusão do empreendedorismo, sendo responsáveis pela criação e preparação de empreendedores, dando a eles o conhecimento e o suporte adequados. Os 
objetivos, neste caso, seriam de mostrar ferramentas que auxiliem no alcance do sucesso, contribuindo para o crescimento do país, além de incentivar as pessoas (especialmente os jovens) a criarem seu próprio negócio ou empreenderem nas organizações em que atuam, o que Dolabela (2003) denomina de intraempreendedorismo.

Jones e English (2004) entendem que é necessário que as pessoas detenham habilidades empresariais e capacidade para lidar com os desafios atuais da vida e um futuro incerto. Seja na escolha da carreira ou outras situações pessoais, os indivíduos podem se beneficiar do aprendizado do empreendedorismo, habilitando-se a resolver problemas, adaptando-se mais facilmente às mudanças.

Para formar novos empreendedores, é importante focar na identificação e no entendimento das suas habilidades. Em uma concepção mais empresarial, a mesma ênfase deve ser dada à inovação e sua importância no processo empreendedor, à utilização de um plano de negócio, identificação de fontes para obter financiamentos, na gestão promover o crescimento orgânico da empresa (DORNELAS, 2001). No entendimento do autor, estes seriam temas (ou disciplinas) que deveriam ser abordados para a formação empreendedora em escolas e universidades.

O contexto atual é propício ao surgimento cada vez maior de empreendedores e por isso a capacitação para tal é prioridade em vários países. No Brasil, por exemplo, é crescente o número de disciplinas de empreendedorismo nos ensinos técnico e universitário (DORNELAS, 2008).

Dolabela (1999) descreve, para o caso brasileiro, alguns motivos para o ensino do empreendedorismo. Os principais seriam: as grandes mudanças nas relações de trabalho; a não adequação do ensino tradicional para a formação de empreendedores; as relações universidade-empresa ainda incipientes no Brasil; a insuficiente percepção da importância das PME's (pequenas e médias empresas) para o desenvolvimento econômico; e, a necessidade das organizações por profissionais empreendedores e a cultura da "grande empresa" que predomina no ensino profissionalizante e universitário.

Para Jones e English (2004), o ensino de empreendedorismo é uma inovação educacional importante que estimula um processo de aprender a empreender. Dolabela (1999) destaca ainda que é necessário criar uma cultura empreendedora na sociedade, e, para isso, o tema empreendedorismo precisa ser apresentado e 
discutido desde os primeiros níveis da educação. Os alunos devem ser educados com base em valores de autonomia, de independência, capacitando-os para inovar, assumir riscos e atuar em ambientes de instabilidade, como os que a sociedade vivencia na atualidade.

\subsection{PESQUISAS NA ÁREA DE EMPREENDEDORISMO}

Mukesh, Rao e Rajasekharan (2018) analisaram o potencial empreendedor dos alunos e a educação para o empreendedorismo no sistema de ensino superior na Índia e constataram que a grande maioria dos jovens com potencial empreendedor latente está deixando as faculdades sem as necessárias habilidades empresariais básicas. Para os autores, a educação para o empreendedorismo no sistema de ensino superior indiano poderia explorar mais o potencial empreendedor dos alunos. Ainda destacam que, no caso indiano, seria necessária maior ênfase na educação para o empreendedorismo no ensino superior, uma vez que a inconsistência em relação à política de desenvolvimento do empreendedorismo pode prejudicar a economia do país como um todo.

Crecente-Romero, Giménez-Baldazo e Rivera-Galicia (2018) pesquisaram a população europeia de menores de 25 anos no ensino superior entre 2009 e 2014 e descrevem que os jovens recém-formados às vezes encontram dificuldades para ingressar no mercado de trabalho devido à superqualificação. $\mathrm{O}$ aumento no número de trabalhadores qualificados implica uma diminuição nos salários. Uma solução para os custos pessoais e econômicos da superqualificação pode ser a criação de trabalho autônomo por meio do empreendedorismo. Por este motivo, os autores destacam a validade da inclusão de princípios de empreendedorismo em todos os níveis de ensino para melhorar a empregabilidade, método desenvolvido por meio da Estratégia UE 2020 (Planejamento da União Europeia).

As universidades são como "motores do crescimento econômico". O impacto econômico das universidades depende, pelo menos em parte, da abordagem do tema empreendedorismo no meio universitário e do sucesso de empreendimentos empresariais afiliados a universidades. O principal agente promotor desse fenômeno é o empreendedor, sujeito dotado de múltiplas características que compõem seu perfil e que atua de uma forma dinâmica e voltada para colher resultados, frutos de 
seus esforços pessoais (HAYTER et al., 2018). Para Rocha e Freitas (2014), a educação empreendedora é destacada como uma das formas mais eficientes de se divulgar a cultura e formar novos empreendedores. Os pesquisadores constataram que os estudantes que participaram de atividades educacionais de formação em empreendedorismo apresentam alterações significativas no perfil empreendedor.

Moraes, Izuka e Pedro (2018) investigaram os efeitos das características empreendedoras e do ambiente universitário na intenção empreendedora do estudante universitário. Os resultados indicam que a intenção empreendedora dos estudantes é influenciada, entre outras coisas, pelo ambiente universitário e pela atitude em relação a assumir riscos. Os autores sustentam que existe uma relação positiva entre o contexto e a educação empreendedora com a intenção empreendedora dos estudantes.

A pesquisa de Lima et al. (2015) se ocupou em identificar formas de se melhorar a educação superior em empreendedorismo no Brasil, focando o caso dos estudantes brasileiros interessados em ser seus próprios patrões, ou seja, em terem seus próprios negócios. Com uma amostra importante, que contemplou 12.604 fundadores intencionais (empreendedores) de um amplo espectro de cursos superiores de 37 instituições de ensino superior públicas e privadas brasileiras, os pesquisadores constataram que os alunos apresentam alta demanda por educação em empreendedorismo e alta intenção empreendedora. Os resultados mostram que sua intenção de empreender e seu nível de crença em serem competentes para empreender são indiferentes à variação do quanto fazem de disciplinas e atividades de educação em empreendedorismo no ensino superior. Por outro lado, há relação significante e positiva entre a intenção empreendedora e a demanda por educação em empreendedorismo. Os autores apontam que a demanda dos estudantes pode ser aproveitada como facilitadora do necessário aperfeiçoamento da educação em empreendedorismo no Brasil.

Outro estudo abrangente realizado no Brasil, foi o da Endeavor Brasil e do SEBRAE, que em 2016 publicaram a quarta edição da pesquisa "Empreendedorismo nas Universidades Brasileiras", que contou com a participação de 2230 alunos e 680 professores pertencentes a mais de 70 instituições de ensino superior de todas as regiões do Brasil. Este estudo objetivou direcionar as estratégias das universidades e das lideranças que trabalham com o tema no Brasil, 
sejam professores ou formuladores de políticas públicas. Além disso, buscou entender como o ensino superior estimula os alunos a serem empreendedores, como preparar melhor os professores e agentes universitários para este desafio, e quais os tipos de ações são executadas atualmente nesse sentido (ENDEAVOR/SEBRAE, 2016).

A pesquisa Endeavor/SEBRAE abordou as perspectivas do aluno (perfil, desejos e desafios), da universidade (oferta de disciplinas de empreendedorismo, iniciativas extracurriculares e a interação com o ecossistema empreendedor local) e dos professores (papel do professor, suas experiências e práticas empreendedoras).

De acordo com a pesquisa, quanto maior o envolvimento com a temática empreendedora, maior a proporção de alunos que realizaram disciplinas relacionadas ao tema. Cerca de $46 \%$ de alunos empreendedores já cursaram essas disciplinas, número superior ao de potenciais empreendedores $(38,8 \%)$, que por sua vez é superior ao de alunos que não pensam em ter um negócio (24\%). Esta informação reforça a importância da abordagem do empreendedorismo no sistema de ensino (ENDEAVOR/SEBRAE, 2016).

Ainda, entre os potenciais empreendedores, a maioria dos alunos (69\%) que pretende empreender em até 3 anos já cursou disciplinas de empreendedorismo, comparada aos alunos que não têm prazo para empreender. Há, então, uma relação direta entre esses dois fatores.

Há um efeito positivo em todos os aspectos de se empreender quando o aluno cursa uma disciplina de empreendedorismo, mesmo que a diferença não seja tão significativa. Por exemplo, $66 \%$ dos alunos acreditam que as disciplinas de empreendedorismo são essenciais para prepará-lo para empreender. Um dos motivos para isso é que a inspiração para empreender destaca-se como tema de $54,4 \%$ das disciplinas de empreendedorismo. Ela tem uma função importantíssima para a cultura empreendedora da universidade ao instigar os alunos a considerarem o empreendedorismo como opção de carreira (ENDEAVOR/SEBRAE, 2016).

Não há apoio para o empreendedor que está iniciando seu negócio, o que poderia ser corrigido caso disciplinas abordassem temas como criação de novos negócios e gestão de pequenos negócios, o que ocorre apenas em 7,6\% e 6,8\% dos casos, respectivamente. O mesmo acontece para o empreendedor que busca expandir com franquias, inovação e tecnologia, temas presentes em apenas 2,9\% e 
$7,6 \%$ das disciplinas de empreendedorismo, respectivamente (ENDEAVOR/SEBRAE, 2016).

Ao mesmo tempo em que são limitadas do ponto de vista do seu conteúdo, também o são em relação à sua acessibilidade. Somente $28,4 \%$ dos universitários já cursaram uma disciplina diretamente relacionada ao empreendedorismo. Entre aqueles que não cursaram, um terço apontou que o principal motivo está relacionado a acesso à disciplina: $21,2 \%$ não o fez, porque o seu curso não oferece a disciplina e 12,7\%, porque sequer sabe se há alguma disciplina de empreendedorismo disponível em sua instituição de ensino. Por outro lado, 61,5\% dos professores afirmaram que sua universidade oferece alguma disciplina de empreendedorismo. É uma divergência que pode indicar, junto aos dados a seguir, que as disciplinas estão concentradas em cursos específicos.

Em cerca de $50 \%$ dos cursos de engenharias e ciências sociais aplicadas (administração e outras), há disciplinas de empreendedorismo. Em contrapartida, outras áreas de conhecimento têm pouquíssima oferta de disciplinas, como ciências agrárias, da saúde, biológicas e humanas - em torno de $30 \%$ de oferta das disciplinas para esses cursos.

Uma maneira de ampliar e democratizar o acesso a elas é permitir que sejam frequentadas por alunos de diferentes cursos, o que é o caso de disciplinas abertas/sem restrições, presentes em somente $35,5 \%$ das instituições. Disciplinas transversais, em que alunos de diferentes cursos interagem na mesma sala de aula, também são adotadas por somente $41,1 \%$ das universidades (ENDEAVOR/SEBRAE, 2016).

Essa troca é importante para aumentar o acesso às disciplinas e também para que o aluno conheça outros alunos de diferentes formações e referências. Empreender é uma prática interdisciplinar, e muitos futuros sócios ou parceiros podem se encontrar em disciplinas de empreendedorismo.

De acordo com os resultados da pesquisa Endeavor/SEBRAE (2016), a maior quantidade de disciplinas de empreendedorismo está disponível nos cursos de administração e negócios (74\%), seguidos pelas engenharias $(56,1 \%)$, outros cursos das ciências sociais aplicadas (48,9\%), ciências exatas e da terra (42,7\%), ciências humanas $(37,1 \%)$, disciplinas abertas/sem restrição $(35,5 \%)$, ciências biológicas (30\%), linguística, letras e artes $(29,3 \%)$, ciências da saúde $(28,9 \%)$ e ciências 
agrárias $(24,3 \%)$.

Cerca de $44 \%$ dos professores afirmam que elas são distribuídas de maneira uniforme durante o curso, estratégia curricular com mais potencial de gerar impacto sobre os alunos, já que terão mais tempo para se preparar e absorver conhecimento e prática. Apesar disso, mais da metade afirma que as disciplinas de empreendedorismo se concentram ou nos últimos semestres do curso $(36,5 \%)$ ou no início (14,1\%). Ambas as formas acabam por não ser, a priori, o melhor para a formação empreendedora dos alunos já que, quando dadas no início, eles ainda têm uma longa jornada na universidade, na qual serão pouco expostos ao tema. Quando ao final, as disciplinas de empreendedorismo, em geral focadas em inspiração e introdução acabam tendo pouco impacto sobre o aluno, pois ele não conseguirá se aprofundar no assunto, visto que estará no fim do seu curso ou mesmo já terá uma carreira encaminhada (ENDEAVOR/SEBRAE, 2016).

São diversas as iniciativas que podem promover e estimular 0 empreendedorismo nas universidades, como atividades de pesquisa (bolsas para pesquisadores, infraestrutura e professores envolvidos com empreendedorismo, comportamento empreendedor), eventos (feiras de empreendedorismo, rodas de conversa com empreendedores, competições de ideias de negócio, planos de negócio e outros) e programas extracurriculares (parques tecnológicos, incubadoras e aceleradoras, serviços de apoio ao negócio, mentorias, laboratórios de empreendedorismo e/ou inovação/criatividade, entre outros).

\section{METODOLOGIA}

Este artigo foi elaborado com a utilização de pesquisas descritiva, bibliográfica e exploratória. A primeira pesquisa descreve as características de determinada população ou fenômeno ou então, estabelece relações entre variáveis (GIL, 2006). De acordo com Vergara (2009), tal tipologia não objetiva explicar os fenômenos que descreve, embora sirva de base para a explicação.

O trabalho utiliza-se de dados secundários oriundos da Pesquisa Endeavor/SEBRAE sobre o "Empreendedorismo nas Universidades Brasileiras", edição do ano de 2016 (quarta edição). Tal pesquisa tem como principal objetivo conscientizar as instituições de ensino superior sobre seu poder de contribuir com o 
desenvolvimento econômico e social do Brasil, atuando como agente-chave do desenvolvimento do ecossistema empreendedor local. Neste trabalho, a finalidade é servir como subsídio para a descrição e análise das informações coletadas.

O estudo da Endeavor/SEBRAE envolveu entrevistas com acadêmicos e professores, relacionados ao tema empreendedorismo em instituições públicas e privadas de todo o Brasil, o que é detalhado na seção seguinte. Como a pesquisa Endeavor/SEBRAE é abrangente em termos de escopo e amplitude, para a realização deste trabalho optou-se por realizar um recorte geográfico (escolha de uma região específica) para sua replicação, abordando parte dos temas elencados na pesquisa original, além de utilizar apenas dados secundários. A Figura 1 apresenta a sistematização da pesquisa.

A pesquisa descritiva foi utilizada para a caracterização da região de estudo, que contemplou o estado de Santa Catarina. A partir desta classificação regional, foram identificadas as instituições com cursos de Administração presenciais e em atividade. Esta pesquisa foi realizada por meio do Cadastro e-MEC de Instituições e Cursos de Educação Superior, base de dados oficial e única de informações relativas às Instituições de Educação Superior - IES e cursos de graduação do Sistema Federal de Ensino. Por meio desta pesquisa, foram identificados 121 cursos de Administração presenciais no estado de Santa Catarina. O procedimento seguinte foi pesquisar os sites destas instituições e buscar as grades curriculares que estão em andamento nos cursos de Administração. Nesta etapa, foi possível coletar informações de 116 cursos, $95,86 \%$ do total de cursos relacionados no portal do e-MEC.

Figura 1 - Sistematização da pesquisa

Etapa 1
Etapa 2
nas Universidades Brasileiras 2016
Delimitação da Região de estudo (Santa Catarina)
Identificação das Universidades e Faculdades que ofertam cursos de
Administração presenciais de nível superior em Santa Catarina
Classificação das instituições quanto sua forma de atuação: pública
ou privada
Pesquisa das grades dos cursos ofertados com relação às disciplinas
de empreendedorismo

Fonte: Os Autores (2017) 
Das informações constantes nos sites, procurou-se conhecer se as instituições são públicas (mantidas com recursos do governo federal, estadual ou municipal) ou privadas (composta por instituições particulares e comunitárias). Para conhecer a estrutura dos cursos, buscou-se identificar a quantidade de semestres (duração) dos mesmos, o número de disciplinas relacionadas ao empreendedorismo e o(s) estágio(s) do curso em que são ofertadas: (i) início - do $1^{\circ}$ ao $3^{\circ}$ semestre; (ii) na metade do curso - $4^{\circ}$ ao $6^{\circ}$ semestre; (iii) ou no final do curso - $7^{\circ}$ semestre em diante.

Relacionado às disciplinas de empreendedorismo, considerou-se apenas a denominação (nome) da disciplina, sem avaliação das ementas. Assim como a pesquisa Endeavor/SEBRAE, foram consideradas disciplinas de empreendedorismo, as que tivessem a palavra "empreendedorismo" em sua denominação e outras que tivessem como título: gestão (e/ou criação) de novos negócios, (elaboração de) plano de negócios, gestão de pequenos negócios, inovação e tecnologia, negócios familiares e franquias. Embora estes tópicos pudessem constar em ementas de diversas disciplinas, foram considerados apenas temas que constassem como disciplinas nas grades/matrizes curriculares, e não como parte de ementas.

Todos os dados utilizados na realização deste artigo são de origem secundária, provenientes de pesquisa bibliográfica, pesquisa Endeavor/SEBRAE e dos sites do e-MEC e das universidades em estudo. A partir das coletas, foram elaboradas tabelas por meio de planilhas eletrônicas (software) com a organização das informações de acordo com: o tipo da instituição (pública ou privada); o tempo de duração dos cursos; quantidade e semestres das que as disciplinas eram ofertadas; título/denominação das disciplinas.

Com a organização das informações em tabelas, foi possível realizar uma análise qualitativa e chegar a constatações mais concretas sobre as características dos cursos de graduação e do ensino do empreendedorismo nos cursos de Administração nas universidades do estado de Santa Catarina.

\section{APRESENTAÇÃO DOS RESULTADOS}

A pesquisa permitiu coletar informações de 116 cursos de Administração oferecidos na modalidade presencial, distribuídos em 48 diferentes cidades no 
Estado de Santa Catarina. Identificou-se que 106 cursos são ofertados por instituições privadas, cerca de $91 \%$ do total, ao passo que instituições públicas ofertam apenas 10 cursos, ou aproximadamente $9 \%$.

Foi possível também identificar a duração desses cursos ofertados. Constatou-se que, dos 116 cursos, 111 são desenvolvidos ao longo de oito semestres, sendo desses 103 de instituições privadas e 8 de públicas; 4 cursos duram nove semestres, sendo 3 deles particulares e 1 público; e em apenas uma universidade pública o curso de Administração é desenvolvido ao longo de dez semestres.

Relacionado ao ensino do empreendedorismo, pela Tabela 1 pode-se identificar que $13 \%$ dos cursos não apresentam disciplina nas suas respectivas matrizes curriculares. Em termos relativos, percebeu-se que $40 \%$ dos cursos de instituições públicas, 4 cursos de um total de 10, não contam com conteúdos empreendedores; contra 10\% das privadas, em que apenas 11 dos 106 cursos não possuem cadeiras de empreendedorismo. A maioria absoluta, ou seja, os demais 101 cursos, que representam $87 \%$, oferece pelo menos uma disciplina com conteúdo empreendedor.

Nota-se que, normalmente, as universidades oferecem apenas uma disciplina de empreendedorismo. Esta situação foi verificada em $71 \%$ dos cursos, sendo possível identificar 3 públicas (30\% do total das públicas) e 79 privadas $(75 \%$ do total de privadas). Na sequência, $9 \%$ dos cursos ofertam duas disciplinas de empreendedorismo (1 público e 10 privados), $6 \%$ ofertam três disciplinas (1 pública e 6 privadas) e apenas uma universidade privada oferece 4 disciplinas de empreendedorismo.

Tabela 1 - Quantidade de disciplinas de Empreendedorismo por curso

\begin{tabular}{l|c|c}
\hline \multicolumn{1}{c|}{$\mathbf{N}^{\circ}$ de Disciplinas } & Quantidade de cursos & \% do total \\
\hline Nenhuma disciplina & 15 & $13 \%$ \\
\hline Uma disciplina & 82 & $71 \%$ \\
\hline Duas disciplinas & 11 & $9 \%$ \\
\hline Três disciplinas & 7 & $6 \%$ \\
\hline Quatro disciplinas & 1 & $1 \%$ \\
\hline
\end{tabular}

Fonte: Dados da pesquisa (2017)

Estes números indicam que a formação de empreendedores não é o foco da maioria dos cursos de Administração de Santa Catarina, uma vez que $84 \%$ dos cursos oferecem apenas uma ou nenhuma disciplina relacionada ao tema, o que é Ágora: R. Divulg. Cient., v. 24, p. 23-43, 2019 (ISSNe 2237-9010) 
insuficiente para inspirar e formar empreendedores.

\subsection{DISCIPLINAS DE EMPREENDEDORISMO E SUA DISTRIBUIÇÃO}

Sobre a distribuição das disciplinas ao longo do curso, conforme já descrito, 13\% (15 cursos) não oferecem conteúdos empreendedores. Assim, para fins descritivos, consideram-se como $100 \%$ os 101 cursos que oferecem disciplinas de empreendedorismo. Verificou-se a maior ocorrência de disciplinas na metade dos cursos, em $39 \%$ dos casos as disciplinas são ofertadas entre o $4^{\circ}$ e $6^{\circ}$ períodos. $\mathrm{Na}$ sequência, $28 \%$ constam no fim das grades curriculares, do $7^{\circ}$ período em diante; $22 \%$ estão no início, do $1^{\circ}$ ao $3^{\circ}$ período; e apenas $11 \%$ estão distribuídas ao longo dos cursos. Tal distribuição pode ser observada na tabela a seguir.

Tabela 2 - Distribuição das disciplinas de Empreendedorismo nos Cursos de Administração

\begin{tabular}{l|c|c}
\multicolumn{1}{c|}{ Disciplinas } & Quantidade de cursos & \% do total \\
\hline Início do curso $\left(1^{\circ}\right.$ ao $3^{\circ}$ semestre $)$ & 22 & $22 \%$ \\
\hline Metade do curso $\left(4^{\circ}\right.$ ao $6^{\circ}$ semestre $)$ & 40 & $39 \%$ \\
\hline Fim do curso $\left(7^{\circ}\right.$ semestre em diante) & 28 & $28 \%$ \\
\hline Distribuídas ao longo do curso & 11 & $11 \%$ \\
\hline
\end{tabular}

Fonte: Dados da pesquisa (2017)

Nos 101 cursos em que há disciplinas de empreendedorismo, foram identificadas 129 disciplinas relacionadas ao tema, sendo 118 nas instituições privadas e 11 nas públicas. Em termos gerais, os títulos que mais aparecem nas grades dos cursos são: Empreendedorismo (109 vezes); e Inovação e Empreendedorismo (23 vezes), conforme apresentado na Tabela 3.

Tabela 3 - Disciplinas de Empreendedorismo e sua frequência nos cursos

\begin{tabular}{l|c}
\multicolumn{1}{c}{ Disciplinas } & Quantidade de cursos em que é ofertada \\
\hline Empreendedorismo & 109 \\
\hline Inovação e Empreendedorismo & 23 \\
\hline Formação/Criação de novos Negócios & 13 \\
\hline Plano de Negócios & 12 \\
\hline Criatividade e Empreendedorismo & 6 \\
\hline Gestão de pequenos negócios & 2 \\
\hline Empreendedorismo Digital & 1 \\
\hline Inovação em tecnologia & 1 \\
\hline Simulação empresarial & 1
\end{tabular}

As disciplinas intituladas como Formação/Criação de Novos Negócios

Ágora: R. Divulg. Cient., v. 24, p. 23-43, 2019 (ISSNe 2237-9010) 
aparecem 13 vezes nas grades dos cursos e Plano de Negócios outras 12 vezes. Os temas Criatividade e Empreendedorismo aparecem integrados em uma mesma matéria em 6 oportunidades. Outras disciplinas que aparecem com menor frequência são: Gestão de Pequenos Negócios (2 vezes), Empreendedorismo Digital (1 vez), Inovação em Tecnologia (1 vez) e Simulação Empresarial (1 vez). Entretanto, outros temas como Franquias e Negócios Familiares não aparecem nenhuma vez nas grades dos cursos pesquisados.

\section{DISCUSSÃO E CONSIDERAÇÕES}

Com a pesquisa realizada com os cursos de Administração no Estado de Santa Catarina, foi possível identificar que, relacionado aos cursos superiores presenciais desta área, há predominância de instituições de ensino particulares, uma vez que mais de $90 \%$ dos cursos são ofertados por este tipo de instituição.

Nota-se também que uma pequena parte dos cursos de Administração (13\%) não oferece nenhuma disciplina de empreendedorismo, sendo que nas instituições públicas é onde se verifica a menor oferta de conteúdos empreendedores. Apenas $50 \%$ dos cursos de instituições públicas oferecem pelo menos uma disciplina de empreendedorismo, ao passo que, nas instituições privadas, $83 \%$ dos cursos contêm disciplinas de empreendedorismo.

A pouca oferta de disciplinas de empreendedorismo, ou a falta delas, pode ser prejudicial à economia do país, pois, conforme destacam Mukesh, Rao e Rajasekharan (2018), os jovens com potencial empreendedor latente deixam as faculdades sem as necessárias habilidades empresariais básicas, essenciais para empreender.

Há uma concentração das disciplinas no meio do ciclo de formação dos acadêmicos. Dos 101 cursos em que há oferta de disciplinas, 22\% oferecem no início dos cursos (do $1^{\circ}$ ao $3^{\circ}$ semestre), $35 \%$ na metade ( $4^{\circ}$ ao $6^{\circ}$ semestre) e $28 \%$ são ministradas no fim ( $7^{\circ}$ semestre em diante), enquanto que em apenas $11 \%$ dos casos as disciplinas estão distribuídas de maneira uniforme na matriz curricular.

As disciplinas de empreendedorismo concentradas no início ou no fim dos cursos acabam por não ser, a priori, o melhor para a formação empreendedora dos alunos, já que no início dos cursos os alunos ainda têm uma longa jornada na 
universidade, na qual serão pouco expostos ao tema. No início, ainda precisam acumular informações e experiências para que possam despertar para o empreendedorismo. Quando ao final, as disciplinas de empreendedorismo, em geral focadas em inspiração e introdução, acabam tendo pouco impacto sobre o aluno, pois ele não conseguirá se aprofundar no assunto, visto que estará no fim do curso ou mesmo já terá uma carreira encaminhada (ENDEAVOR/SEBRAE, 2016).

A melhor combinação seria, de acordo com a Endeavor/SEBRAE (2016), a distribuição ao longo do curso. A distribuição de maneira uniforme durante o curso é a estratégia curricular com mais potencial de gerar impacto sobre os alunos, já que terão mais tempo para se preparar, absorver conhecimento e prática, além de buscar conhecimentos complementares e necessários para a jornada empreendedora.

Como destacaram Crecente-Romero, Giménez-Baldazo e Rivera-Galicia (2018), a inclusão de princípios de empreendedorismo em todos os níveis de ensino pode melhorar a empregabilidade, uma vez que os jovens recém-formados às vezes encontram dificuldades para ingressar no mercado de trabalho devido à superqualificação. Uma solução para este problema e para a escassez de empregos existentes no mundo poderia ser a criação de trabalho autônomo por meio do empreendedorismo (DOLABELA, 1999; DORNELAS, 2008).

No que se refere aos conteúdos sobre empreendedorismo, os principais temas/nomenclaturas que constam nas grades dos cursos são: Empreendedorismo (65\%), Inovação e empreendedorismo (13,5\%), Formação/Criação de Novos Negócios (8\%), Plano de Negócios (7,5\%) e Criatividade e Empreendedorismo (3,5\%). Estas disciplinas têm função importantíssima para a cultura empreendedora das universidades e dos cursos, ao instigar os alunos a considerarem o empreendedorismo como uma opção para a carreira profissional (ENDEAVOR/SEBRAE, 2016).

De acordo com a Endeavor/SEBRAE (2016), depois que os alunos se tornam empreendedores em potencial, e posteriormente empreendedores de fato, é possível perceber que as instituições de ensino superior brasileiras não possuem uma estrutura completa que os apoiem em sua jornada. Não há apoio para o empreendedor que está iniciando seu negócio, o que poderia ser corrigido caso disciplinas abordassem temas como criação de novos negócios e gestão de 
pequenos negócios, por exemplo.

Apesar de matérias relacionadas ao empreendedorismo constarem em $87 \%$ dos cursos pesquisados, a formação de empreendedores pode não ser efetiva, uma vez que em mais de $50 \%$ dos casos as disciplinas dessa área são ministradas no início ou no fim dos cursos. Esta metodologia, como citado pela pesquisa da Endeavor/SEBRAE (2016), não prepara de maneira adequada o acadêmico. Além disso, a oferta de apenas uma única disciplina em todo o curso também prejudica a formação de empreendedores, visto que não há um aprofundamento maior nessa área e, como a pesquisa aponta, essa é a realidade da grande maioria dos cursos de Administração em Santa Catarina.

A ausência de disciplinas como franquias, negócios familiares, empreendedorismo social e gestão de pequenos negócios, também chamam a atenção nas grades curriculares dos cursos pesquisados. Estes temas podem eventualmente constar nas ementas das disciplinas, entretanto, isto não foi avaliado nesta pesquisa, uma vez que demandaria pesquisar as ementas de todas as disciplinas ofertadas nos 116 cursos. Além disso, o fato de o tema constar na ementa não significa que seja explorado em sala de aula ou relacionado com a necessidade do empreendedor, uma vez que a aplicação dependeria da iniciativa, formação e experiência do professor.

Ainda que a disciplina de empreendedorismo conste em grande parte dos cursos de Administração ofertados em Santa Catarina, a formação de empreendedores parece não representar uma prioridade ou o foco nas suas respectivas estratégias de atuação. Isto porque, na grande maioria, trata-se de uma disciplina isolada que, sem o desenvolvimento de outras atividades que possam servir de complemento, acabam tornando esta iniciativa pouco efetiva.

Da mesma forma, proporcionar iniciativas extracurriculares, como incubadoras e aceleradoras, mentorias, laboratórios de empreendedorismo e/ou inovação/criatividade, parques tecnológicos, entre outros, se tornam de pouca efetividade caso os alunos não tenham a possibilidade de receber uma formação/qualificação para empreender.

Aspectos importantes para estimular e disseminar a prática empreendedora seriam realizar uma reflexão sobre a conexão que existe entre as universidades e o mercado. Conforme indica a pesquisa Endeavor/SEBRAE (2016), um passo 
fundamental para formar mais e melhores empreendedores é aproximar as universidades do mercado, dos empreendedores e da comunidade em geral. Isso fará com que as instituições desenvolvam ações que estejam mais alinhadas com a demanda dos universitários e do mercado.

Outros aspectos importantes a considerar são a formação e a experiência empreendedora dos professores, uma vez que estes podem exercer influência sobre os alunos, podendo ser mentores ou inspiradores para os empreendedores. Os docentes são os promotores do empreendedorismo nas universidades e precisam fazer parte do ecossistema empreendedor das cidades, por isso, a experiência empreendedora (aliada ao conhecimento teórico), é fundamental para que esta atividade tenha pleno êxito.

Hayter et al. (2018) destacam que as universidades podem impulsionar o crescimento econômico, o que depende, pelo menos em parte, da abordagem do tema empreendedorismo no meio universitário e do sucesso de empreendimentos empresariais afiliados a universidades. A intenção empreendedora dos estudantes é influenciada, entre outras coisas, pelo ambiente universitário e pela atitude em relação a assumir riscos (SCHUMPETER, 1982; BECKER; LACOMBE, 2003; MORAES; IZUKA; PEDRO, 2018). Ainda, há relação significante e positiva entre a intenção empreendedora e a demanda por educação em empreendedorismo. Os autores apontam que a demanda dos estudantes pode ser aproveitada como facilitadora do necessário aperfeiçoamento da educação em empreendedorismo no Brasil (LIMA et al., 2015).

Este trabalho teve por objetivo apresentar algumas pesquisas relacionadas à educação para o empreendedorismo desenvolvida nas universidades e envolveu em seu escopo mais de uma centena de cursos de graduação presencial em Administração do estado de Santa Catarina. O estudo, levou em consideração principalmente a intensidade com que o assunto é abordado nos cursos (quantidade de disciplinas). Embora considere-se também o semestre em que as disciplinas são ofertadas, não é possível inferir algo em termos qualitativos, de forma que, para isto, seria necessário considerar outras variáveis como: experiências e práticas empreendedoras dos professores, interação da universidade com o mercado e a sociedade, existência de incubadoras, aceleradoras, dentre outras. A parte qualitativa apresenta-se como uma importante oportunidade para o desenvolvimento 
de novas pesquisas.

A formação de mais e melhores empreendedores é de interesse da sociedade e esta pesquisa contribui para o conhecimento acerca da atuação das instituições de ensino superior, públicas e privadas, como promotoras do empreendedorismo. Os resultados poderão ser utilizados como subsídio para a reflexão e/ou tomada de decisões de todos os agentes envolvidos e interessados na formação de empreendedores.

\section{REFERÊNCIAS}

BARON, R. A.; SHANE, S. A. Empreendedorismo: uma visão do processo. São Paulo: Cengage Learning, 2011.

BARRETO, L. P. Educação para o empreendedorismo. Educação Brasileira, v. 20, n. 41, p. 189-197, 1998.

BECKER, G. V.; LACOMBE, B. M. B. Colocando luz em quem tem "ideias luminosas": competências do empreendedor de base tecnológica. ENANPAD; 27. Atibaia, 2003. Anais... Atibaia, 2003.

BRASIL. Ministério da Educação. Cadastro e-MEC de Instituições e Cursos de Ensino Superior. Disponível em: <http://emec.mec.gov.br/> Acesso em 11 de março de 2017.

CRECENTE-ROMERO, F.; GIMÉNEZ-BALDAZO, M.; RIVERA-GALICIA, L. F. Can entrepreneurship channel overqualification in young university graduates in the European Union? Journal of Business Research, v. 89, n. 4, p. 223-228, 2018.

DOLABELA, F. Oficina do empreendedor: a metodologia de ensino que ajuda a transformar conhecimento em riqueza. São Paulo: Cultura, 1999.

. Pedagogia empreendedora. São Paulo: Cultura, 2003.

. A corda e o sonho. Revista HSM Management, n. 80, p. 128-132, 2010.

DORNELAS, J. C. A. Empreendedorismo: transformando ideias em negócios. Rio de Janeiro: Campus, 2001.

Emprendedorismo: transformando ideias em negócios. Rio de Janeiro:

Elsevier, 2008.

ENDEAVOR/SEBRAE. Empreendedorismo nas universidades brasileiras. Endeavor Brasil / SEBRAE, 2016.

GIL, A. C. Como elaborar projetos de pesquisa. 3.ed. São Paulo: Atlas, 1996.

HAYTER, C. et al. A. Conceptualizing academic entrepreneurship ecosystems: a 
review, analysis and extension of the literature. The Journal of Technology Transfer, v. 43, n. 4, p. 1039-1082, 2018.

HISRICH, R. D.; PETERS, M. P. Empreendedorismo. 5.ed. Porto Alegre: Bookman, 2004.

JONES, C.; ENGLISH, J. A Contemporary approach to entrepreneurship education. Education + Training, v. 46, n. 8/9, p. 416-423, 2004.

LIMA, E. et al. Ser seu próprio patrão? Aperfeiçoando-se a educação em empreendedorismo. Revista de Administração Contemporânea, v. 19, n. 4, p. 419-439, 2015.

McCLELLAND, D. C. n-Achievement and entrepreneurship: a longitudinal study. Journal of Personality and Social Psychology, v. 1, n. 4, p. 392-396, 1965.

MORAES, G. H. S. M.; IZUKA, E. S. PEDRO, M. Effects of entrepreneural characteristics and university environment on entrepreneural intention. Revista de Administração Contemporânea, v. 22, n. 2, p. 226-248, 2018.

MUKESH, H. V.; RAO, A. S.; RAJASEKHARAN, P. K. Entrepreneural potential and higher education system in India. The Journal of Entrepreneurship, v. 27, n. 2, p. 258-276, 2018.

NORTH, D. Instituciones, cambio institucional y desempeño económico. México: Fondo de Cultura Económica, 1990.

ROCHA, E. L. C.; FREITAS, A. A. F. Avaliação do ensino de empreendedorismo entre estudantes universitários por meio do perfil empreendedor. Revista de Administração Contemporânea, v. 18, n. 4, p. 465-486, 2014.

SCHUMPETER, J.A. The creative response in economic history. The Journal of Economic, v. 7, n. 2, p. 149-159, 1947.

SCHUMPETER, J. A. Teoria do desenvolvimento econômico: uma investigação sobre lucros, capital, crédito, juro e ciclo econômico. São Paulo: Abril Cultural, 1982.

SIQUEIRA, M. M.; GUIMARÃES, L. O. Estratégias empreendedoras de negócios tupiniquins. ENANPAD; 26. Salvador, 2002, Anais... Salvador, 2002.

TOYOSHIMA, S. Instituições e desenvolvimento econômico: uma análise crítica das ideias de Douglass North. Estudos Econômicos, v. 29, n. 1, p. 95-112, 1999.

VERGARA, S. C. Projetos e relatórios de pesquisa em administração. 11.ed. São Paulo: Atlas, 2009.

Artigo recebido em: 08/01/2018

Artigo aprovado em: 12/04/2019

Artigo publicado em: 22/04/2019 